\title{
Pattern of addiction and its relapse among habitual drug abusers in Lahore, Pakistan
}

Sadia Batool', Iram Manzoor', Shamaila Hassnain' ', Aslam Bajwa', Muslim Abbas ', Maha Mahmood ' and Hina Sohail'

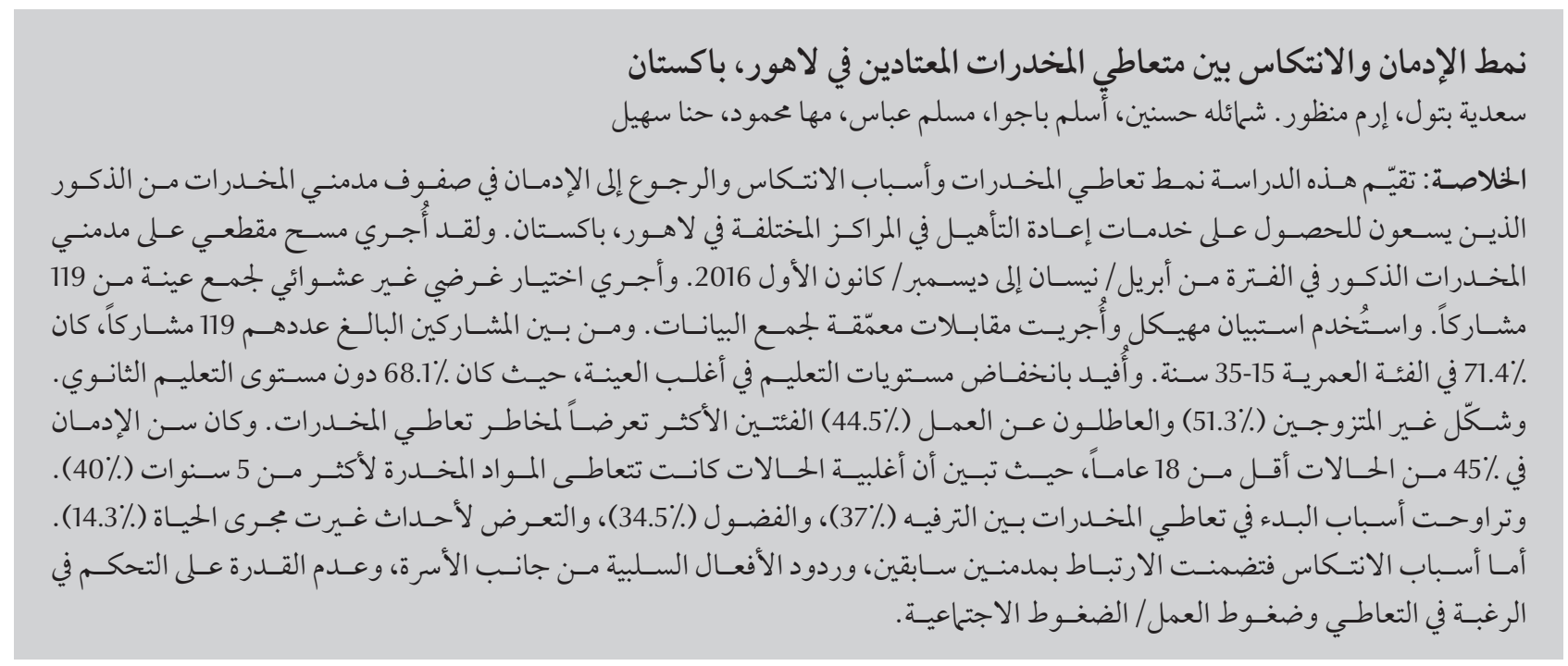

ABSTRACT This study assessed the pattern of drug abuse and the reasons for relapse of addiction among male drug addicts seeking rehabilitative services in different centres in Lahore, Pakistan. A cross-sectional survey was conducted on male drug abusers from April to December 2016. Nonprobability purposive sampling was done to collect a sample of 119 participants. A structured questionnaire and in-depth interviews were used for data collection. Out of 119 participants, $71.4 \%$ were in the age group 15-35 years. Educational levels were low in the majority, with $68.1 \%$ below secondary education. Unmarried (51.3\%) and unemployed (44.5\%) participants were at the greatest risk of using drugs. The age of addiction in $45 \%$ of patients was $<18$ years and $40 \%$ had been abusing substances for $>5$ years. Reasons for starting drug abuse were recreation (37\%), curiosity (34.5\%), and lifechanging events (14.3\%). Reasons for relapse included association with former addicts, negative reactions from family, inability to manage the craving and work/social stress.

\section{Schéma de dépendance et de rechute parmi les toxicomanes habituels à Lahore, Pakistan}

RÉSUMÉ La présente étude avait pour objectif d'évaluer les schémas d'abus de substances psychoactives et les causes de rechute parmi les hommes toxicomanes recherchant des services de réadaptation dans différents centres de Lahore, au Pakistan. Une enquête transversale a été conduite sur les utilisateurs de substances psychoactives de sexe masculin entre avril et décembre 2016. Un échantillonnage non probabiliste par choix raisonné a été réalisé afin d'établir un échantillon de 119 participants. Un questionnaire structuré et des entretiens approfondis ont été utilisés pour la collecte de données. Sur les 119 participants, 71,4 \% appartenaient au groupe d'âge des 15-35 ans. Les niveaux d'éducation étaient faibles dans la plupart des cas, 68,1\% n'ayant pas atteint I'enseignement secondaire. Les hommes célibataires (51,3\%) et chômeurs (44,5\%) étaient exposés à un risque accru de toxicomanie. L'âge de la mise en place de la dépendance était inférieur à 18 ans chez $45 \%$ des patients, $40 \%$ d'entre eux consommant des substances psychoactives depuis plus de 5 ans. L'aspect récréatif (37\%), la curiosité $(34,5 \%)$ et les changements de vie (14,3\%) comptaient parmi les raisons pour lesquelles les patients commençaient à utiliser des substances psychoactives. Les causes de rechute incluaient le regroupement avec d'anciens toxicomanes, les réactions négatives de la famille, l'incapacité à gérer le manque, et le stress professionnel et social. 


\section{Introduction}

Addiction is defined as a maladaptive pattern of substance use leading to clinically significant impairment or distress, occurring any time in the same 12 -month period. It is manifested by tolerance, withdrawal and other symptoms (1).

Approximately 15.9 million people inject drugs worldwide, with the largest numbers found in China, America and Russia (2). Annual prevalence of all illicit drug use in Pakistan was reported as 6\% in 2013 (3). The annual prevalence in Pakistan of cannabis use is $3.6 \%$, opioids $2.4 \%$, tranquilizers $1.4 \%$, amphetamine $0.08 \%$, solvents $0.03 \%$ and cocaine $0.01 \%$. (3). The highest number of intravenous drug abusers among all provinces is in Punjab (4), which includes a high ratio of polydrug abuse among addicts in Lahore using heroin and opium together (3).

Internationally, two thirds of patients with addiction have a coexisting mental health problem (5). In male heroin users in Lahore, parental disharmony, paternal absence or maternal illiteracy has been shown to increase risk of addiction (6). Psychosocial factors like loneliness, parental coldness and peer pressure are major contributors to addiction (7). Curiosity to try new things is one of the most common reasons reported by drug users themselves (8).

Alcohol consumption accounts for loss of healthy years of life globally, and in high-income countries causes $\sim 19 \%$ of disability-adjusted life years and $\sim 27 \%$ of premature deaths among young people (9). If children initiate drug or alcohol abuse at age 10-11 years, there is a greater chance that they will be trapped in addiction at age 1718 years (10). Parents who have heavy alcohol consumption are more likely to have children who abuse alcohol (11). Other childhood premorbid traits that determine continuation of substance abuse in adulthood are boldness and less socialization (12).

Family ties have an important role in the recovery process from addiction. Family support and concern for one's own health are the most important motivating factors for quitting abuse (13), whereas socializing with the same peer groups and easy availability of drugs are the biggest reasons for relapse (14).

According to the National Institute on Drug Abuse of Pakistan, only 11.2\% of the addicts who need treatment actually seek it (15). Treatment of drug addiction and rehabilitation services are provided through a wide range of public and private institutes in Lahore. The present study targeted male addicts seeking rehabilitation services in Lahore to assess the practice of drug abuse and reasons for relapse. Few studies have been conducted in this area of research and there is a dearth of scientific evidence to target strategies to tackle this important public health issue.

\section{Material and methods}

A cross-sectional study using a mixedmethods technique was conducted among addicts currently undergoing treatment in Lahore. Total duration of the study was 6 months (March-August 2016). One hundred and nineteen addicts from different rehabilitative institutes in Lahore were selected by using a purposive sampling technique.

A structured questionnaire was developed for collection of quantitative data and personal interviews were transcribed for collection of qualitative data. Analysis was done using SPSS version 20 for the quantitative variables. Thematic analysis was carried out for qualitative questions. To explore the factors and determinants of addiction among the participants, initial codes were generated in a systematic fashion. Codes were used to create "bigideas" (or themes) from each interview and data was coded on the basis of recurrence of similar responses. Qualitative analysis, including thematic and content analysis, was carried out for qualitative data. A subset of transcripts was also double coded, that is, two members of the research group coded the same transcript to reduce personal bias. Disagreements and insights were discussed and alternative interpretations were incorporated in the analysis. Finally, interview transcripts were indexed and mapped on the basis of recurring major themes with corresponding sub-themes. To ensure reliability, 2 researchers read the interviews separately and agreed on the coding framework. A general introduction to research design, interviewing skills, gaining trust and adherence to ethical boundaries were discussed at the Institutional Review Board.

\section{Results}

Forty-two (35.3\%) respondents were aged 18-24 years, 43 (36.1\%) 25-34 years, $20(16.8 \%) 35-44$ years and 14 $(11.8 \%) \geq 45$ years. Sixty-one $(51.3 \%)$ respondents were single, 53 (44.5\%) married and 5 (4.2\%) divorced. Two (1.7\%) respondents were illiterate, 29 (24.4\%) were educated up to grade 5, $52(43.7 \%)$ up to grade $8,28(23.5 \%)$ matric to grade 14 and 8 (6.7\%) postgraduate, which means that $68.1 \%$ were below secondary level. Fifty-three (44.5\%) respondents were unemployed and 66 (55.5\%) were employed before being admitted to the facility. Only one of them was already in service and undergoing treatment after being granted medical leave from his employer. Approximately $42 \%$ had income less than Rs 30,000 (US\$300). The majority of the respondents belong to lower socioeconomic groups. Approximately $41 \%$ of the respondents have income between US\$ 100 to US\$300.

Fifty-three (44.5\%) of the respondents started using drugs when they were aged $<18$ years, $43(36.1 \%)$ at $18-25$ years, $15(12.6 \%)$ at $25-35$ years and 
$8(6.7 \%)$ at $>35$ years, which showed that $82.8 \%$ of the respondents started abusing drugs before age 25 years. The reasons for initial drug use were recreation $(n=46,38.6 \%)$, curiosity ( $n$ $=41,34.5 \%)$, life-changing event $(n=$ $17,14.3 \%)$ and peer pressure $(\mathrm{n}=15$, $12.6 \%)$. The mode of intake was sniffing $(\mathrm{n}=39,32.8 \%)$, oral ingestion $(\mathrm{n}=37$, $31.1 \%)$, inhalation $(n=29,24.3 \%)$ or intravenous injection $(\mathrm{n}=14,11.8 \%)$. Forty-seven (39.5\%) respondents used drugs for $>5$ years, $46(38.7 \%)$ for $1-5$ years, $13(10.9 \%)$ for 6 months- 1 year and 13 (10.9\%) for < 6 months. Sixtyfour $(53.8 \%)$ respondents used a single drug and 55 (46.2\%) multiple drugs. Ninety-four (79.7\%) respondents reported that their drug use had been influenced by friends and 11 (9.3\%) by family. Other influences included spouses, media and work colleagues. The most common drugs used were charas $(\mathrm{n}=52,44.4 \%)$, heroin $(\mathrm{n}=$ 48, 41\%), hashish $(\mathrm{n}=39,33.3 \%)$ and alcohol $(\mathrm{n}=33,28.2 \%)$, followed by sedative pills, cocaine and naswar (n $=14,12 \% ; n=4,3.5 \%$ and $n=3,2.5 \%$, respectively).

Sixty-six (55.5\%) respondents were admitted to rehabilitation centres once, $23(19.3 \%)$ were admitted twice and 30 $(25.2 \%) \geq 3$ times. Eighty-four (70.6\%) respondents reported family involvement and 35 (29.4\%) no family involvement. Twenty-six (21.8\%) respondents had an associated chronic disease and 93 (78.2\%0 did not, and 32 (26.9\%) had an associated psychiatric illness and 87 (73.1\%) did not. Fifty-eight (48.7\%) respondents had drugs provided by drug dealers, 29 (24.4\%) by friends, 16 (13.4\%) by pharmacies, $14(11.8 \%)$ by work colleagues and $2(1.7 \%)$ by family.

Eighty-five (72\%) respondents admitted to being financially burdened because of drug abuse, and often resorted to borrowing money from friends or taking from their family, especially their parents. However, a large number (98, $83 \%)$ were now concerned for their health and were motivated to find a cure.

We conducted in-depth interviews to establish the reasons for relapse into drug abuse. Relapse was commonly reported among all 119 respondents. The following themes were identified based on the participants' responses.

\section{Sleepy friends, sleepy places}

Sixty-five (50\%) participants blamed their friends or social connections for their relapse into drug abuse. Thirtyeight $(32 \%)$ respondents said that friends were their source of provision of drugs, and 95 (80\%) respondents reported that they obtained information about drugs from friends. Participants reported that when they returned to the same community and encountered the same people, they slowly began to indulge in the same harmful activities as before.

\section{Family grief and sadness}

Most of the participants said they experienced rude behaviour from their family and wider society, which had a negative effect. One participant relapsed solely due to taunts he faced after returning to the rehabilitation centre. They spoke about many aspects such as divorce, feeling hated by relatives, family bereavement, living in poverty, and being unemployed.

\section{Inability to control craving}

Thirty-six (30\%) participants reported that they were devoid of any social support after returning to familiar locations, circumstances and people, which meant that they were not able to control their craving. Work stress and the same environment contributed negatively to relapse. Some were misusing the detoxification centres to eliminate tolerance developed by their bodies, to achieve euphoria and the same high that they felt when they used drugs for the first time. This means that they never intended to be cured but, in complete knowledge of their disease, to use the treatment centres to their own advantage.

\section{Sick of being sick}

Forty-eight (40\%) participants reported that they had come willingly to the rehabilitation centre for treatment; the others stated that they were being brought forcefully by family members. One participant was sick of spending so much money on drugs. A government employee said that alcohol was readily available in their circumstances; that they normally drank to relax and smoked cigarettes with heroin and other drugs to raise their energy levels and performance. The respondent now had tremors and hallucinations and decided to seek treatment. One young participant stated that he was undergoing treatment because he did not want to die, although he also stated his belief that there was no cure for addiction. Becoming a parent was a wake-up call for one participant.

\section{Dissatisfaction with doctors}

One participant complained that he was not educated sufficiently about his disease and was not counselled properly by his doctors, which resulted in relapse into drug abuse.

\section{Work and social stressors}

The participants included healthcare professionals, for example, a dentist and a paramedic serving at the emergency department of a government hospital. Facing the same stressors that made them initiate drug use was also a cause of relapse, for example, work stress and relationship breakdown. The mass media was considered to play a negative role in their promotion of unrealistic images of relationships, which acted as a social stressor.

\section{Discussion}

In Pakistan, 4.25 million drug users required interventional treatment in 2011 
(15). This signifies the burden of disease due to addiction. There is a strong taboo associated with addiction in Pakistan, particularly among the younger age group (< 18 years) (16). Women are particularly socially stigmatized if they report drug use and seek treatment (17), and there are no separate rehabilitation centres for female drug users. Our study targeted 3 different rehabilitation centres in Lahore. The various methods of addiction commonly practiced include sniffing, oral ingestion, inhalation and intravenous injection. Our study highlighted that $\sim 50 \%$ of the participants were either sniffing or inhaling the drugs. On the contrary, the National Institute on Drug Abuse states that injection and smoking are the most common methods of drug administration (18).

We found that the majority of participants started abusing drugs before 18 or between 18 and 25 years of age. Similar findings were reported in a study in which $92.9 \%$ of the participants reported substance use before the age of 25 years (19). Drug abuse at an early age can have detrimental effects on the psychological, physical and social development of the individuals concerned (20), leading to troubled teenage years, poor academic performance and conflicts with family and friends.

Another important indicator associated with drug abuse is the duration of use. Approximately half of the participants in our study reported using drugs for $>5$ years. A study conducted in Rawalpindi, Pakistan $(21,22)$ had similar findings substantiating the fact that mostly chronic drug abusers seek rehabilitation services. Strategies should be devised to trace drug abusers in the early stage of their addiction to encourage them to seek help for cessation and counselling.

The main reasons for initiation of drug abuse highlighted by the participants in our study were recreation and curiosity. A study conducted in Malaysia in 2013 highlighted similar reasons, confirming the findings of our study (23). Lack of recreational activities can be one of the factors that trigger substance abuse. More emphasis should be placed by provincial and national government on the provision of recreational activities and places of entertainment. Such initiatives will provide alternative means to dissipate energy and become involved in healthy leisure activities. The issue of curiosity can be addressed by health education campaigns targeted at individual, group and mass levels.

The main limitation of our study was the lack of female participants. Their inclusion would have provided an opportunity to explore further the factors associated with initiation of drug abuse and associated factors of low compliance to treatment and sociocultural aspects of drug abuse. However, lack of availability of female participants and the strong social and cultural stigma and sensitivity associated with female addiction made it difficult to recruit female participants.

In conclusion, drug addiction is a problem that is escalating globally among younger age groups $(<18$ years). This can have negative implications on their physical, psychological and social development. Policies and health awareness campaigns should be scaled up to address the prevalence of drug abuse among young people and highlight the factors associated with initiation of substance abuse. A multisectoral approach should be adopted and addiction cessation services should be prioritized at the primary healthcare level.

\section{Funding: None.}

Competing interests: None declared.

\section{References}

1. Diagnostic and statistical manual of mental disorders. 4th edition. Washington, DC: American Psychiatric Association; 2000.

2. Mathers B, Degenhardt L, Philipps B, Weissing L, Hickman M, Strathdee SA, et al. Global epidemiology of injecting drug use and HIV among people who inject drugs: a systematic review. Lancet. 2008 Nov 15; 372(9651):1733-45. PMID:18817968.

3. Drug use in Pakistan 2013. Vienna: United Nations Office on Drugs and Crime; 2013 (http://www.unodc.org/documents/ pakistan//Survey_Report_Final_2013.pdf, accessed 25 April 2017).

4. Narcotics and Pakistan. Consultative Sessions on the Draft Anti-Narcotics Policy 2010. Pakistan Institute of Legislative Development and Transparency; 2010 (http://www.pildat.org/publications/publication/GovernanceAssessment/ NarcoticsandPakistan-ConsultativeSessionsontheDraftAntiNarcoticsPolicy2010.pdf, accessed 25 April 2017).

5. Park S, Kim Y. Prevalence, correlates, and associated psychological problems of substance use in Korean adolescents. BMC Public Health. 2015;16:79. PMCID:PMC4728773.
6. Siddique F, Mann AA, Ali T. Influence of social factors on drug use behavior in Punjab. Pakistan. Pak J Nutr. 2012;11(11):1099100.

7. van der Zwaluw CS1, Scholte RH, Vermulst AA, Buitelaar JK, Verkes RJ, Engels RC. Parental problem drinking, parenting, and adolescent alcohol use. J Behav Med. 2008 Jun;31(3):189200. PMID:18189121.

8. Racz J. The role of the curiosity in interviews with drug users. Forum Qual Soc Res. 2008 May;9(2):16 (http://www.qualitative-research.net/index.php/fqs/article/view/423/917, accessed 25 April 2017).

9. Chan YF, Dennis ML, Funk RR. Prevalence and comorbidity of major internalizing and externalizing problems among adolescents and adults presenting to substance abuse treatment. J Subst Abuse Treat. 2008;34(1):14-24. PMID:17574804.

10. Hawkins JD, Graham JW, Maguin E, Abbott R, Hill KG, Catalano RF. Exploring the effects of age of alcohol use initiation and psychosocial risk factors on subsequent alcohol misuse. J Stud Alcohol. 1997 May;58(3):280-90. PMID:9130220. 
11. Rossow I, Keating P, Felix L. McCambridge J. Does parental drinking influence children's drinking? A systematic review of prospective cohort studies. Addiction. 2016;111(2):204-17. PMID:26283063.

12. Hicks B, Lacono W, McGue M. Identifying childhood characteristics that underlie premorbid risk for substance use disorders: socialization and boldness. Dev Psychopathol. 2014 Feb;26(1):141-57. PMID:24280373.

13. Vignesh BT, Singh AK, Mohan SK, Murthy S, Joshi A. Association between socio-demographics and alcohol dependence. Glob J Health Sci. 2014 Jan 23;6(3):16-26. PMID:24762342.

14. Golestan S, Abdullah HB, Ahmed NB, Anjomshoa A. Environmental factors influencing relapse behavior among adolescent opiate users in Kerman (a province in Iran). Glob J Hum Soc Sci. 2010;10(4):71-6. (http://socialscienceresearch.org/index. php/GJHSS/article/view/67/46).

15. Drug facts. Treatment statistics. Revised March 2011. Bethesda, MD: National Institute on Drug Abuse (https://www.drugabuse.gov/publications/drugfacts/treatment-statistics, accessed 25 April 2017).

16. Zaman M, Razzaq S, Hassan R, Qureshi J, ljaz H, Hanif M, et al. Drug abuse among the students. Pak J Pharm Res. 2015 Jan 1;1(1):41-7 (http://pjpr.net/index.php/pjpr/article/ view/21/10, accessed 25 April 2017).

17. Shafiq M, Shah Z, Saleem A, Siddiqi MT, Shaikh KS, Salahuddin FF, et al. Perceptions of Pakistani medical students about drugs and alcohol: a questionnaire-based survey. Subst Abuse Treat Prev Policy. 2006 Oct 25;1(1):31. PMID:17064420.

18. Kuria MW. Factors associated with relapse and remission of alcohol dependent persons after community based treatment. Open J Psychiatry. 2013;3:264-72 (http://file.scirp.org/pdf/ OJPsych_2013043010042069.pdf, accessed 25 April 2017).

19. Drugs, brains, and behavior: the science of addiction. Bethesda, MD: National Institute on Drug Abuse (https://www. drugabuse.gov/publications/drugs-brains-behavior-scienceaddiction/drug-abuse-addiction, accessed 25 April 2017).

20. Newcomb MD, Bentler PM. Consequences of adolescent drug use: impact on the lives of young adults. Newbury Park, CA: Sage Publications; 1988.

21. Masood S, Sahar NU. An exploratory research on the role of family in youth's drug addiction, Health Psychol Behav Med. 2014 Jan 1;2(1):820-32. PMCID:PMC4346037 20:

22. Tam C, Foo YC. A qualitative study on drug abuse relapse in Malaysia: contributory factors and treatment effectiveness. Int J Collabor Res Intern Med Public Health. 2013;5(4):217-32.

23. Malik A, Nawaz S, Tahir A, Ahmed S, Ashraf S, Hanif N et al. Knowledge and awareness of harmful effect of substance abuse among usersand non-users: a cross-sectional study from Bari Imam. J Pak Med Assoc. 2012 Apr;62(4):412-5. PMID:22755297. 